\title{
ACERVO SEF: O PATRIMÔNIO \\ ARQUITETÔNICO DA USP EM PROJETOS E FOTOGRAFIAS.
}

SABRINA STUDART FONTENELE COSTA, UNIVERSIDADE DE SÃO PAULO, SÃO PAULO, SÃO PAULO, BRASIL.

Arquiteta e urbanista pela Universidade Federal do Ceará. Mestre e Doutora pela FAU-USP. Pesquisadora colaboradora de pós-doutorado do IFCH Unicamp. Coordenadora da equipe de Construções, Conjuntos e Sítios do Centro de Preservação Cultural da USP desde 2012. E-mail: fontenel@usp.br.

DOI

http://dx.doi.org/10.11606/issn.1980-4466.v0iesp21p204-218 


\section{ACERVO SEF: O PATRIMÔNIO ARQUITETÔNICO DA USP EM PROJETOS E FOTOGRAFIAS. \\ SABRINA STUDART FONTENELE COSTA}

\section{RESUMO}

O Centro de Preservação Cultural (CPC) realizou uma profunda pesquisa sobre a gestão e preservação do patrimônio construído da Universidade de São Paulo (USP) a partir de um levantamento no Acervo de Projetos da Superintendência de Espaços Físicos (SEF). Essa unidade, que se originou a partir do antigo Fundo de Construção da USP (Fundusp), criado na década de 1960, é a responsável pelo planejamento, organização, fiscalização e preservação dos espaços da Universidade e guarda um acervo estimado em 400 mil desenhos em papel, além de documentos fotográficos, memoriais e arquivos digitais mais recentes. A diversidade de informações sobre os edifícios selecionados - entre edifícios históricos doados ou vendidos para a Universidade de São Paulo e aqueles construídos pela própria instituição - apresentava-se como um desafio para a coleta de dados que deveriam revelar os princípios gerais de projeto e intervenção no patrimônio construído da USP. A partir do recorte instituído - bens tombados ou em processo de tombamento - foi possível levantar as informações necessárias para estabelecer uma cronologia das transformações dos edifícios focalizados desde sua construção até as intervenções mais recentes.

\section{PALAVRAS-CHAVE}

Desenho de arquitetura. Patrimônio arquitetônico. Universidade (arquitetura). Patrimônio universitário. 


\section{THE SEF ARCHIVE: USP'S ARCHITECTURAL HERITAGE IN PROJECTS AND PHOTOGRAPHS. \\ SABRINA STUDART FONTENELE COSTA}

\section{ABSTRACT}

The Cultural Preservation Center (CPC) conducted extensive research on the management and preservation of USP's building heritage based on a survey from SEF (Superintendence of Physical Spaces). This agency, originated from Fundusp (USP Building Fund) created in the 1960s, is responsible for planning, organizing, monitoring and preserving the University spaces, which holds an estimated collection of 400,000 drawings on paper, photographic documents, memorials and digital files. The diversity of information about the selected buildings, whether historic buildings donated or sold to the University of São Paulo or those built by the institution, presented a challenge to collecting data to reveal the general principles of design and intervention on the University's cultural heritage. Using a defined sample, assets already listed as heritage (or going through that process), it was possible to gather the necessary information to establish a timeline of the changes the buildings in scope went through, from their construction to the most recent interventions.

\section{KEYWORDS}

Architectural design. Architectural heritage. University (architecture). University heritage. 


\section{O CPC E O PATRIMÔNIO CONSTRUÍDO DA UNIVERSIDADE DE SÃO PAULO}

A pesquisa aqui tratada foi desenvolvida pela equipe do Centro de Preservação Cultural da USP, órgão da Pró-Reitoria de Cultura e Extensão, que desde 2004 atua frente ao patrimônio universitário. Estabelecido desde maio de 2004, durante a gestão da Profa. Dra. Ana Lucia Duarte Lanna, no edifício conhecido como "Casa de Dona Yayá", imóvel tombado nas instâncias municipal e estadual de preservação, o CPC tem se destacado pelas ações de identificação, conservação, valorização e difusão do patrimônio da USP no que diz respeito aos imóveis tombados ou em processo de tombamento, acervos artísticos, museológicos, bibliográficos e arquivísticos e às coleções especiais e científicas pertencentes às diversas unidades e órgãos da USP.

O CPC teve origem em uma comissão criada em 1986: a Comissão de Patrimônio Cultural. Segundo o professor Nestor Goulart Reis Filho, “(...) naquele momento, discutia-se um pedido de autorização para venda em hasta pública do edifício Paula Souza, o primeiro construído para a Escola Politécnica, logo após sua fundação" (REIS FILHO, 1999, p. 22). Desde o primeiro momento, tem desenvolvido ações de reconhecimento e preservação desse patrimônio, em alguns casos apresentados em formato de publicações. O Centro de Preservação Cultural tem en- 
tre suas atribuições a de "propor, fomentar, desenvolver ou coordenar programas de documentação e de levantamento técnico do patrimônio cultural da USP" e "opinar sobre propostas de obras e intervenções em bens listados e/ou de interesse cultural, assim como dar parecer sobre seu uso, no que respeita à preservação ${ }^{1 "}$.

A pesquisa realizada no Acervo de Projetos da Superintendência de Espaços Físicos da USP (SEF) promoveu a atualização de um dos primeiros levantamentos realizado pelo CPC, ainda na década de 1990, apresentado na base BENS do banco de dados do órgão e publicado como um volume da série Cadernos CPC, Bens Imóveis Tombados e em Processo de Tombamento da USP (1999), que registrava os atributos do patrimônio cultural edificado da USP. Essa primeira pesquisa apresentava os bens tombados ou em processo de tombamento (no total de 17 bens) e as características fundamentais para compreendê-los: data de construção, autor do projeto, histórico, descrição e dados arquitetônicos, registro e razões do tombamento.

Em 2013, uma parceria estabelecida entre o CPC e a SEF estimulou uma consulta aos órgãos de preservação sobre os bens tombados ou em processo de tombamento da Universidade de São Paulo, de maneira a atualizar a lista existente nas duas instituições. Na lista encaminhada à SEF, constavam 19 bens, apresentados a seguir:

\section{BENS TOMBADOS}

1. Faculdade de Arquitetura e Urbanismo da USP

2. Vila Penteado (FAU Maranhão)

3. Edifícios Rui Barbosa e Joaquim Nabuco (Centro Universitário Maria Antonia)

4. Casa de Dona Yayá

5. Engenho São Jorge dos Erasmos

6. Museu Paulista

7. Museu de Zoologia

8. Museu Republicano de Itu 
9. Faculdade de Direito

10. Faculdade de Medicina

11. Associação Atlética Oswaldo Cruz

12. Instituto Oscar Freire

13. Campus de Ribeirão Preto

14. Conjunto da Escola de Agricultura Luiz de Queiroz

15. Bens em processo de tombamento

16. Departamento de História e Geografia - FFLCH-USP

17. Centro de Práticas Esportivas

18. Departamento de Mecânica da Escola Politécnica

19. Escola de Metalurgia da Escola Politécnica

20. Instituto de Astronomia e Geofísica

O Acervo de Projetos da SEF implanta-se em sala no térreo do mesmo edifício onde se encontram as instalações da SEF (localizado em dois pavimentos do prédio da antiga Reitoria). A parceria estabelecida entre SEF e CPC permitiu ainda que os funcionários deste órgão pudessem ter acesso à sala do Acervo e a uma sala de reunião onde o material levantado era analisado.

Durante os três meses de pesquisa, o CPC trabalhou com duas equipes que avaliavam as informações do conjunto de desenhos e fotografias. Enquanto a equipe de arquitetura (coordenada pela especialista Sabrina Fontenele) analisava o conteúdo das pranchas buscando traçar uma cronologia das fontes documentais dos espaços físicos da USP a partir de seus projetos de construção, manutenção e intervenção apresentados no Acervo, a de acervos (coordenada pela especialista Cibele Monteiro) avaliava o estado de conservação dos documentos, seus principais danos e patologias. Neste artigo, iremos nos debruçar sobre a pesquisa de arquitetura ${ }^{2}$.

2. Para informações mais específicas sobre a pesquisa completa, ver SILVA, Cibele Monteiro; COSTA, Sabrina Studart Fontenele. Para um inventário dos edifícios tombados ou em processo de tombamento da USP no Acervo da SEF. In: LIRA, José Tavares Correia de (org.). Patrimônio Construído da USP: preservação, gestão e memória. São Paulo, Edusp, 2014. 
A Universidade de São Paulo foi oficialmente estabelecida a partir do Decreto Estadual 6.283, de 25 de janeiro de 1934, assinado pelo governador Armando Salles de Oliveira. Mesmo antes de sua fundação, alguns cursos superiores já funcionavam na Faculdade de Direito (1827), na Escola Politécnica (1894) na Faculdade de Medicina (1912) e na Escola Superior de Agricultura (1899). Estas foram incorporadas ao projeto da Universidade de São Paulo desde o início. É certo que poucos edifícios contaram com sede própria logo nos primeiros anos de funcionamento, como é o caso da Faculdade de Direito, sediada no Largo de São Francisco, e da Escola Politécnica, situada em um antigo palacete na Rua Três Rios, ambas na cidade de São Paulo. No entanto, alguns edifícios, com programas diferentes dos educacionais, tiveram que sofrer alterações, a exemplo da Vila Penteado, antiga residência que a partir de 1948 passou a abrigar a sede da Faculdade de Arquitetura e Urbanismo.

A partir da década de 1940, iniciam-se as discussões para a construção de um campus universitário que reunissem os cursos na região do Butantã. Diversos arquitetos foram contratados para planejar e propor os novos espaços físicos educacionais da Cidade Universitária (tema contemplado no texto da professora Mônica Junqueira de Camargo, nesta mesma edição da Revista (PC) sob a coordenação de Helio Duarte e com recursos do então criado Fundo para Construção da Cidade Universitária (Fundusp).

Entrevistas realizadas com funcionários da SEF em 2013 indicam que a origem do acervo está diretamente relacionada à rotina de trabalho do Fundusp: desenvolvimento e revisão de projetos, acompanhamento de obra, entre outros. A SEF, responsável pelo planejamento, organização, fiscalização e preservação dos espaços físicos da USP, guarda um acervo estimado em 400 mil desenhos em papel, além de documentos fotográficos, memoriais e arquivos digitais mais recentes. Assim, abrigam-se projetos construídos ou não, de espaços físicos novos ou adaptados para atividades da USP (Figura 1). 


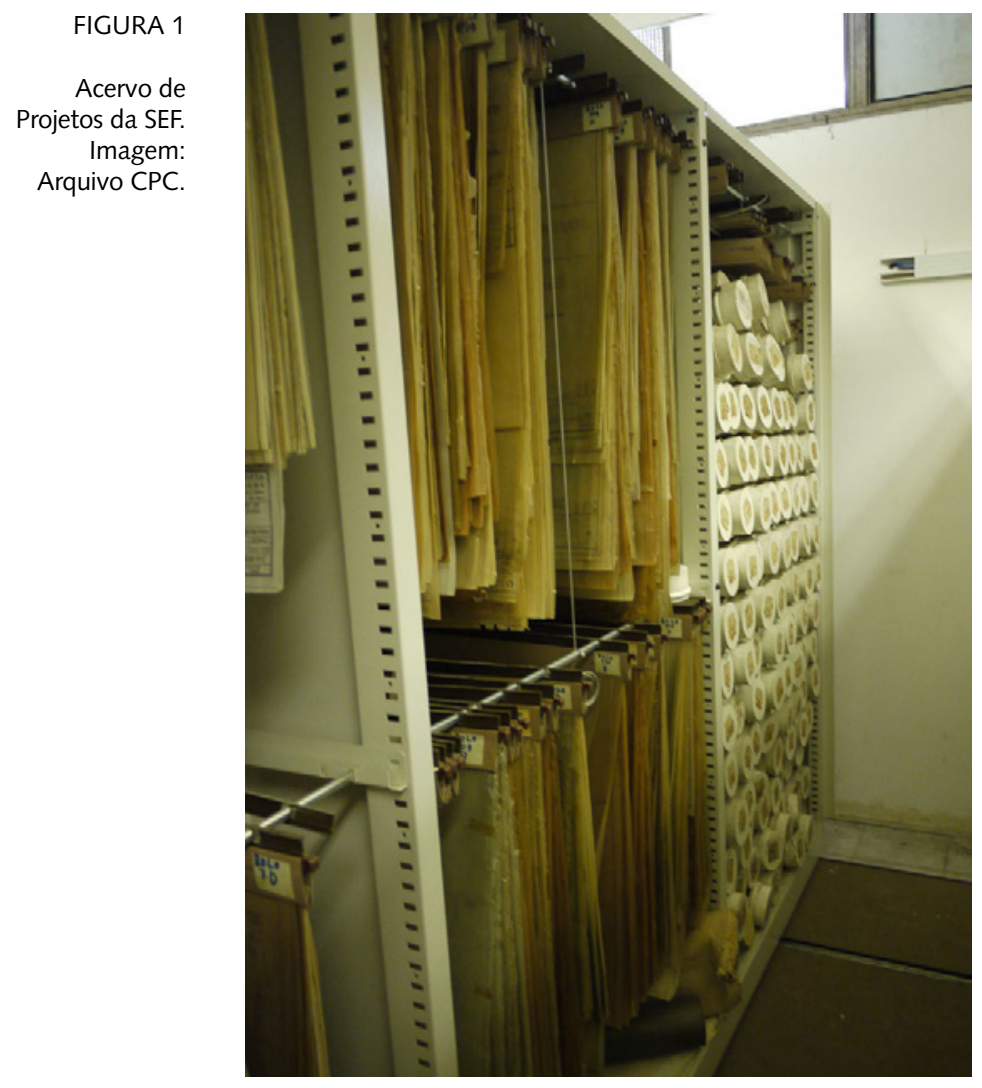

O Acervo é formado por documentos dos mais variados tipos e suportes: projetos, memoriais, fotografias, diapositivos, negativos, fotografias digitais, entrou outros. O conjunto representa parte das ideias e discussões, construídas ou não, da história da Universidade. Diante dessa dimensão, foi necessário estabelecer um recorte específico do material a ser analisado - informações sobre os 19 bens tombados ou em processo de tombamento da USP - e um método de trabalho que garantisse a análise dos documentos retirados de seu espaço de guarda, sem comprometer seu estado de conservação e o registro de dados diversos em um mesmo suporte.

Para a análise das informações sobre os 19 bens tombados ou em processo de tombamento foi realizado um levantamento entre mais de 4.000 desenhos e mil fotografias históricas. Agrupados em réguas ou 
rolos (que armazenavam entre 20 e 40 pranchas), referem-se, em sua maioria, aos desenhos executivos (arquitetura e instalações), mas também estudos preliminares e anteprojetos. Fichas de papel - armazenadas em uma caixa de acrílico - relacionam as unidades de ensino ou pesquisa com as réguas e rolos equivalentes. No entanto, não existe um cadastro que identifique e relacione o conteúdo de cada conjunto disposto nos suportes. O que significa que a busca por um desenho específico depende do manuseio de diversas réguas e rolos, o que torna a situação dos documentos ainda mais frágil.

Os desenhos eram deslocados da sala do Acervo para a sala de trabalho da equipe, onde as informações referentes a cada suporte eram registradas em fichas. Estas reuniam informação sobre cada grupo de desenho, possibilitando ainda registros específicos de informações que se destacassem (Figura 2).

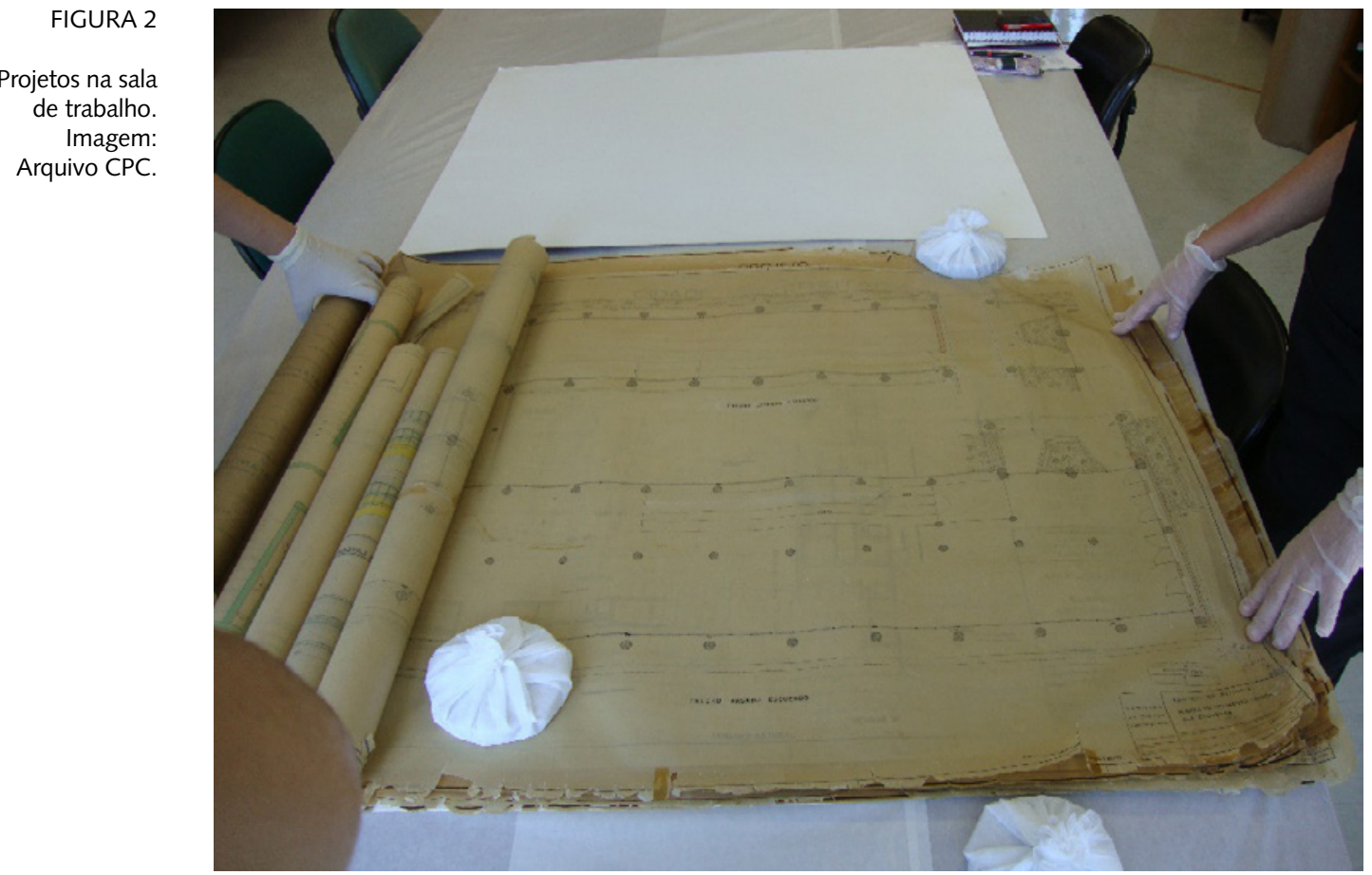


A documentação fotográfica - armazenada em envelopes - apresenta momentos históricos da construção da Universidade ao retratar canteiros, maquetes, obras concluídas, vistas aéreas da universidade e os interiores e exteriores dos edifícios. A análise das fotografias e desenhos armazenados no Acervo possibilitou compreender partes da história da USP até então pouco exploradas.

\section{PESQUISA SOBRE A GESTÃO DO PATRIMÔNIO CONSTRUIIDO}

A ficha utilizada ao longo da pesquisa teve como influência direta outra utilizada no setor de projetos da Biblioteca da Faculdade de Arquitetura e Urbanismo da USP. Uma visita técnica realizada nessa unidade possibilitou uma interessante troca de experiências que colaborou com a organização da metodologia de trabalho.

As pranchas e rolos agrupam desenhos de períodos e conteúdos diferentes. Assim, de maneira a organizar informações sem relação direta (por exemplo, detalhamento técnico de um pilar do período de construção com a reforma de um auditório realizado três décadas depois), optou-se por distribuir os dados levantados em três colunas que organizariam os dados por período do imóvel: projeto original (construção), intervenções parciais e restauração. Acreditava-se que essa distribuição das informações no momento da pesquisa poderia agilizar seu processamento e, por sua vez, fornecer uma ideia inicial sobre a gestão do edifício.

A ficha desenvolvida apresentava campos a serem preenchidos com informações referentes ao documento no Acervo - classificação, tombo, suporte, número de folhas - assim como informações sobre o projeto - autor, ano, responsável técnico do projeto e registros sobre a elaboração do projeto (plantas, cortes, elevações e detalhes). Também foram levantados dados fundamentais para compreender a gestão dos espaços físicos: períodos de intervenção, empresas contratadas com frequência e espaços representados. Além disso, buscou-se registrar informações sobre a produção gráfica do projeto, assim como observações quanto à qualidade gráfica dos desenhos a partir de dados como natureza do desenho e técnicas utilizadas (Figura 3). 


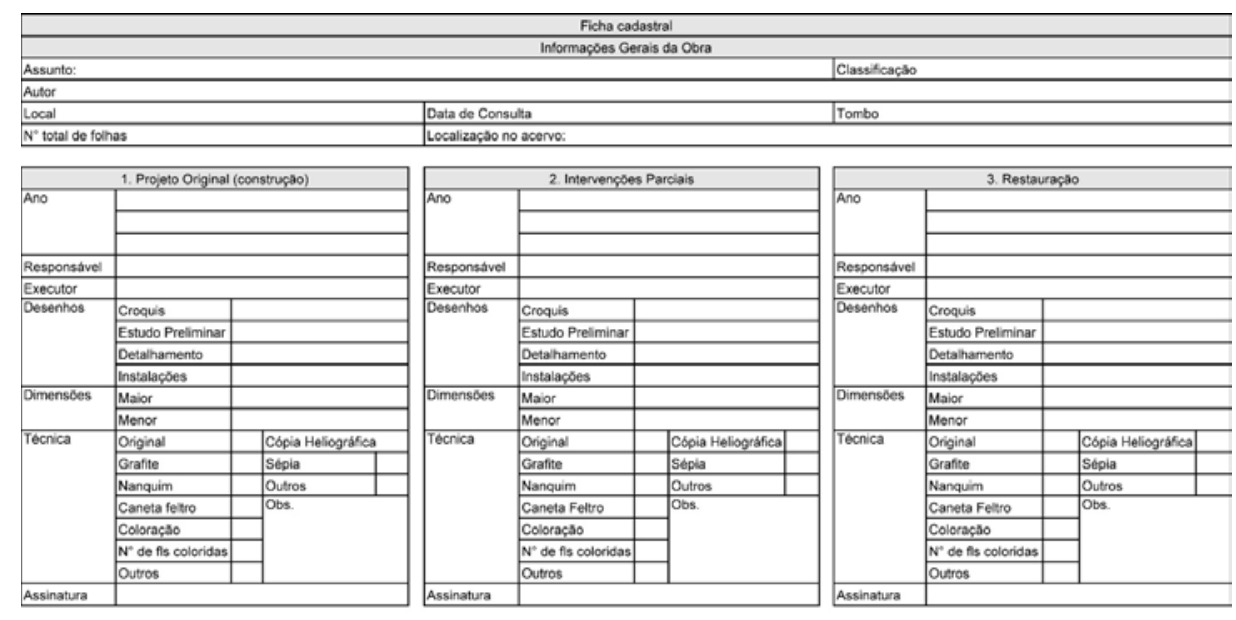

Notas (desenhos selecionados e justicativa)

Os carimbos dos desenhos, em alguns casos mais de um em uma mesma prancha, traziam dados relevantes sobre as empresas e responsáveis pelo projeto e pela obra. O Fundusp, detentor do acervo, evidentemente, destacava-se pela frequência com que aparecia como responsável, mas foi possível observar, em diversos casos, a assinatura de um profissional contratado.

Foi realizado, ainda, o registro fotográfico de cada um dos desenhos analisados. Buscava-se assim criar uma ferramenta a que se pudesse recorrer em caso de dúvidas, por ocasião do processamento dos dados, sem acesso direto ao Acervo.

\section{RESULTADOS INICIAIS DA PESQUISA}

A pesquisa foi apresentada na publicação do CPC Patrimônio Construído da USP: preservação, gestão e memória (2014, Cadernos CPC, 10) em um capítulo que exibe os dados compilados sobre os projetos analisados dividido entre os seguintes campos: natureza, autenticidade, responsável e estado de conservação do acervo. Além disso, para melhor compreensão do período de produção dos projetos, foi apresentada uma cronologia dos projetos organizada por décadas. 
Essa cronologia permitiu compreender de maneira mais clara as diversas fases dos edifícios históricos: construção, ampliações, reformas, restauros etc. Estes dados foram complementados pelos desenhos selecionados - que representam as diversas etapas dos bens - e constituem uma pequena amostra da qualidade gráfica dos materiais e das propostas neles representados.

A investigação no Acervo revelou a riqueza de um material artístico e documental pouco conhecido e reconhecido. Especialmente os croquis e alguns anteprojetos apresentavam uma riqueza de cores, traços e elementos gráficos próprios de uma concepção mais livre do projeto arquitetônico. Um exemplo disso seria a perspectiva da Raia Olímpica, realizada em nanquim com colorido de pigmento em cera, que apresentava o carimbo do Fundusp e representava a apropriação desse espaço esportivo da Cidade Universitária de maneira bastante expressiva.

Os desenhos do levantamento técnico da Casa de Dona Yayá, de autoria de Luis Antônio Magnani e Victor Hugo Mori, em 1988, foram executados em nanquim e representam com rigor as qualidades arquitetônicas do casarão do Bexiga. Apresentava o carimbo do escritório responsável e do antigo Fundusp. Alguns desses exemplares foram apresentados a um público mais abrangente ao compor a exposição $O$ tempo das construções realizada pelo CPC e exibida na Casa de Dona Yayá entre outubro de 2013 e março de 2014, que se valeu diretamente com desenhos e fotografias do Acervo da SEF para traçar uma história dos espaços físicos da Universidade (Figuras 4 e 5).

É importante ainda ressaltar que, além do levantamento das informações sobre os projetos arquitetônico, foi realizado pela equipe do CPC o levantamento do estado de conservação dos documentos, onde se registrava danos e patologias presentes nos desenhos, entre manchas, fungos, perda de informação (por rasgos nas pranchas), entre outros (SILVA; COSTA, 2014). Foram digitalizadas e analisadas mais de mil fotografias históricas relativas aos bens pesquisados que se referiam aos mais variados aspectos, como: canteiro, obra, implantação, interiores e exteriores das construções. 
FIGURA 4

Casa de Dona Yayá Imagem: Acervo SEF.

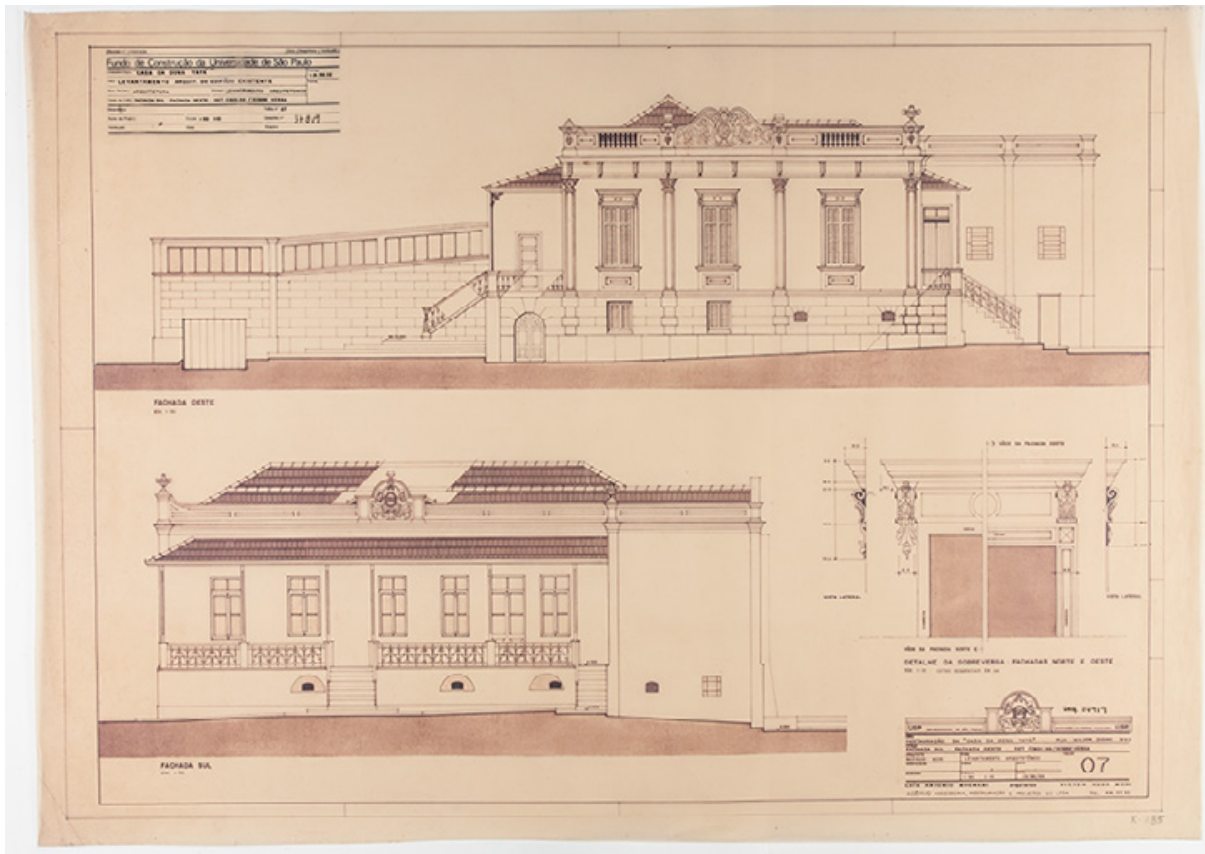

FIGURA 5

Projeto da Raia

Olímpica da USP.

Imagem: Acervo SEF.

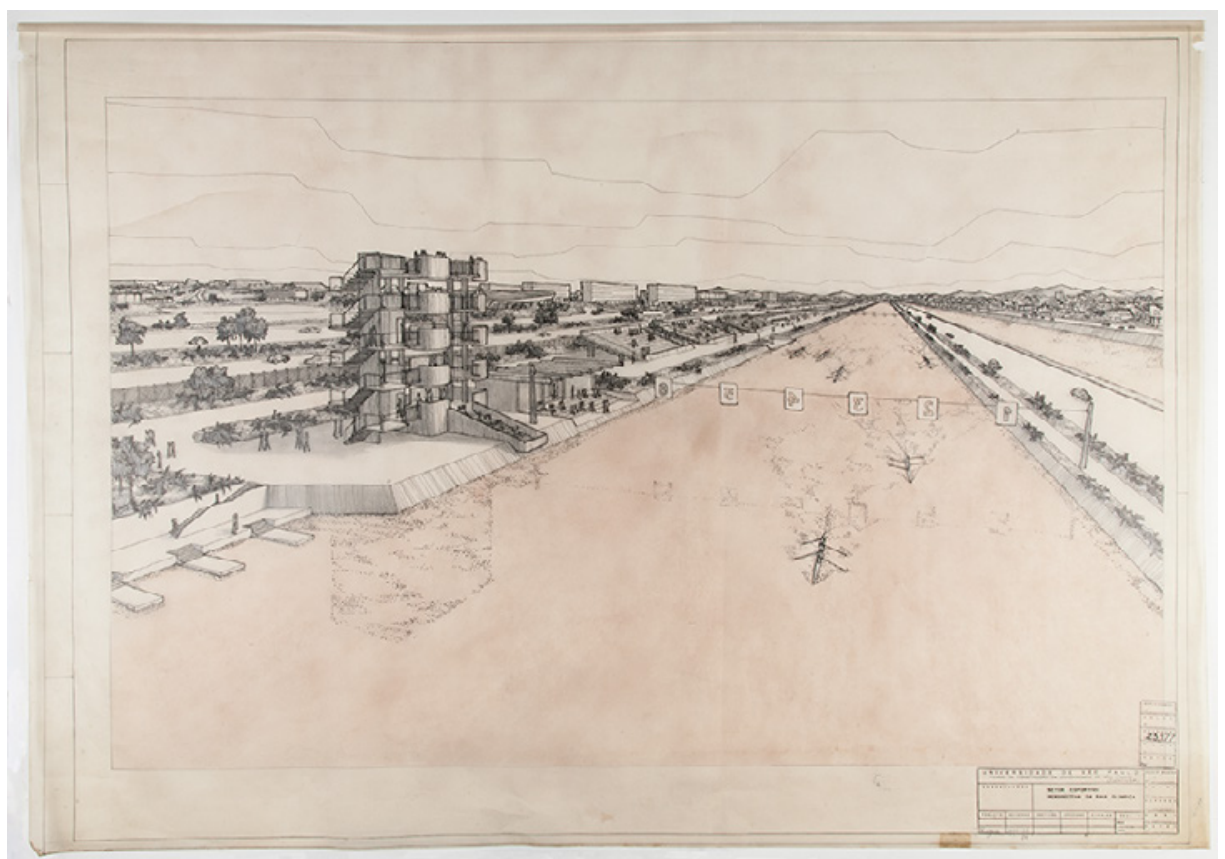




\section{CONSIDERAÇÕES FINAIS}

Além de atualizar uma das primeiras pesquisas do CPC, que se relaciona diretamente com a atuação do órgão frente ao patrimônio cultural da Universidade de São Paulo, a pesquisa realizada no Acervo de Projetos da SEF possibilitou uma discussão sobre a gestão de seu patrimônio construído, bem como de sua memória. Debruçar-se sobre as propostas - executadas ou não - mostrou-se como uma oportunidade de compreender a preservação dos bens culturais ao longo dos anos e em diversas etapas.

Podemos assumir algumas conclusões a partir dos dados apresentados no inventário da publicação. A primeira delas é que a maior parte dos desenhos referentes ao recorte estabelecido (19 bens culturais) refere-se aos edifícios construídos na Cidade Universitária da USP, uma vez que o Fundusp gerenciou o projeto e a construção desses edifícios; enquanto que a maior parte dos registros que se referem aos edifícios fora do CUASO são levantamentos arquitetônicos ou reformas para adaptação dessas construções, mas em número consideravelmente menor. Para se ter ideia desse dado, enquanto o edifício da Faculdade de Arquitetura e Urbanismo tem 352 desenhos armazenados, o Museu Paulista tem 69, a Casa de Dona Yayá tem 25 e o Museu Republicano Convenção de Itu tem 10. Ainda vinculado à participação do Fundusp, o levantamento apontou que $41,20 \%$ do total de desenhos apresentam o carimbo dessa instituição.

Uma segunda constatação seria a do período da produção dos documentos. A grande maioria (42,7\% do total) se refere à década de 1960 , momento de planejamento e execução da Cidade Universitária; e da década de 1970 (38,28\%), sendo a grande maioria documentos vinculados ao projeto do Centro de Práticas Esportivas da USP, concebido nessa época. Importante afirmar ainda que a partir do ano 2000, todos os projetos da SEF passaram a ser desenvolvidos eletronicamente, sendo que as versões impressas dos arquivos de projeto não são armazenadas neste Acervo, portanto, não foram analisados pela equipe do CPC.

Do total de desenhos analisados, 45,30\% são referentes aos projetos de arquitetura (croquis, estudos preliminares e projetos executivos), enquanto que os $54,70 \%$ restante dizem respeito a desenhos de instalações, estrutura e outros detalhamentos. 
A pesquisa desenvolvida pelo CPC possibilitou diversos desdobramentos, desde a utilização dos dados levantados para criação de subsídios para construção dos Planos de Conservação de Bens Culturais (a exemplo do que tem acontecido na FAU-USP), assim como pesquisas com a temática mais ampla (a exemplo do trabalho coordenado pela professora Mônica Junqueira e Miguel Buzzar, que tem apoio da Fapesp).

\section{REFERÊNCIAS}

COSTA, Sabrina Studart Fontenele; CARVALHO, Mariana Pinheiro de; LEONARDI, Marina;

SILVA, Cibele Monteiro da; ROMA, Bruno de Andréa; CAPELLARI, Rafael Lima. Exposição "O tempo das construções" explora a memória construtiva da USP. São Paulo, Revista CPC, n. 17, pp. 108115. Disponível em: <http://www.revistas.usp.br/cpc/article/view/69157>. Acesso em: 25 fev. 2016.

LIRA, José Tavares Correia de. Patrimônio edificado como patrimônio universitário: o CPC e a USP. In: LIRA, José Tavares Correia de (org.). Patrimônio construído da USP: preservação, gestão e memória. São Paulo: Edusp, 2014. (Cadernos CPC, 10)

REIS FILHO, Nestor Goulart. O CPC e os imóveis de interesse cultural. In: Lourenço, Maria Cecília França (org.). Bens imóveis tombados ou em processo de tombamento da USP. São Paulo: Edusp; Imprensa Oficial, 1999.

SILVA, Cibele Monteiro; COSTA, Sabrina Studart Fontenele. Para um inventário dos edifícios tombados ou em processo de tombamento da USP no Acervo da SEF. In: LIRA, José Tavares Correia de (org.). Patrimônio construído da USP: preservação, gestão e memória. São Paulo, Edusp, 2014. (Cadernos CPC, 10)

\section{Recebido}

24/03/2016

Aprovado

$16 / 06 / 2016$ 